\title{
Brief report: a comparison of child mental health inequalities in three UK population cohorts
}

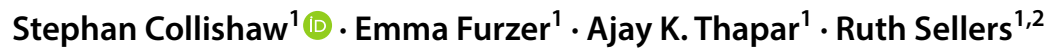

Received: 11 September 2018 / Accepted: 30 January 2019 / Published online: 8 March 2019

(c) The Author(s) 2019

\begin{abstract}
There are substantial health disparities between children from low and higher income families. The study aimed to test changes in child mental health inequalities across three large UK population cohorts of 11-year-old children assessed in 1999, 2004 and 2012 as part of the British Child and Adolescent Mental Health Surveys and Millennium Cohort Study. Child mental health was assessed using parent and teacher versions of the Strengths and Difficulties Questionnaire. There were substantial differences in parent and teacher reported symptom scores between children from low and higher income families in each cohort. Differences in parent-reported symptoms increased over time (ES 0.35 [95\% CI 0.20, 0.49] in 1999, ES 0.39 [95\% CI 0.17, 0.61] in 2004, ES 0.54 [95\% CI 0.49, 0.58] in 2012); cohort interaction: $p=0.01$ ). This study found that marked child mental health inequalities exist. The mental health gap between advantaged and disadvantaged children has not reduced over the last 20 years and may be getting worse.
\end{abstract}

Keywords Inequality $\cdot$ Child mental health $\cdot$ Time trends $\cdot$ Cohort

\section{Introduction}

Alleviating inequalities in child health is a major policy priority internationally, including for successive UK governments [1,2]. However, evidence highlights stark and growing inequalities in child physical health [3]. Less is known about inequalities affecting children's mental health and whether these have changed over time, but there is some evidence that inequalities in adolescent emotional problems increased in the second half of the twentieth century [4]. Our aim here was to test family income inequalities in child mental health problems in the UK in the twenty-first century.

Stephan Collishaw

collishaws@cardiff.ac.uk

1 Child and Adolescent Psychiatry, Division of Psychological Medicine and Clinical Neurosciences, MRC Centre for Neuropsychiatric Genetics and Genomics, Cardiff University School of Medicine, Hadyn Ellis Building, Maindy Road, Cardiff CF244HQ, Wales, UK

2 Rudd Centre for Adoption Research and Practice, School of Psychology, University of Sussex, Brighton, England, UK

\section{Methods}

Three large unselected UK population cohorts of 11-yearold children were compared: 1999 British Child and Adolescent Mental Health Survey (BCAMHS 1999, $N=928$ ), 2004 British Child and Adolescent Mental Health Survey (BCAMHS 2004, $N=670$ ) and the Millennium Cohort Study (MCS) 2012 sweep $(N=11,474)$. The use of identical symptom screens allows for valid 'like-with-like' comparison of the prevalence of child mental health problems across unselected population cohorts [5], and parents and teachers provide unique and complementary information about children's mental health [6]. Parents and teachers in each study completed the widely used and extensively validated Strengths and Difficulties Questionnaire (SDQ) to assess mental health [7]. The SDQ total score includes 20 items assessing conduct problems, emotional problems, hyperactivity, and peer problems. For cross-cohort comparisons of mental health inequalities, parent- and teacher-rated total SDQ scores were each standardised within each cohort (mean $=0, \mathrm{SD}=1$ ) to allow direct comparison of effect sizes (i.e. SD unit differences). Parents provided information about gross household income, and analyses compared families below or above the bottom quintile of incomes within each cohort. Standard survey-specific weights accounted 
for non-response and sample stratification (MCS). Linear regression models tested differences in SDQ total scores within each cohort, and cross-cohort comparisons (using standardised SDQ outcome scores) tested the interaction between cohort and low family income.

\section{Results}

There was no overall change in levels of child mental health problems reported by parents (total SDQ symptom scores: $1999=8.34$ [95\% CI 7.98, 8.70], $2004=7.85$ [7.40, $8.31], 2012=8.12[8.02,8.23], p=0.29)$ or by teachers $(1999=6.15$ [95\% CI 5.72, 6.57], $2004=6.13[5.59,6.66]$, $2012=5.92[5.80,6.05], p=0.48)$. There were substantial income inequalities in child mental health within each cohort (see Fig. 1). In addition, there was a significant cohort by income interaction for parent reports (beta $=0.074[95 \%$ CI $0.020,0.176], p=0.01$ ) showing that income inequalities varied across the study period. Comparing mental health problem scores for children from low and higher income families in each cohort, we observed that effect sizes increased by $54 \%$ across the study period (ES 0.35 [95\% CI $0.20,0.49$ ] in 1999, ES 0.39 [95\% CI 0.17, 0.61] in 2004, ES 0.54 [95\% CI 0.49, 0.58] in 2012). For teacher reports, there were substantial differences between poor and nonpoor children within each cohort (ES 0.41 [95\% CI 0.23, 0.59] in 1999, ES 0.56 [95\% CI 0.22, 0.90] in 2004, ES 0.57 [95\% CI 0.51, 0.62] in 2011). The cohort by income interaction tended in the same direction, but was not significant (beta $=0.055$ [95\% CI - 0.013, 0.165], $p=0.09$ ).
Fig. 1 Standardized mental health problem scores for three nationally representative samples of 11-year-old children from high and low-income families. Mean $z$ scores and 95\% CIs. (a parent reports; b teacher reports)
Panel A: Parent-rated child mental health problems

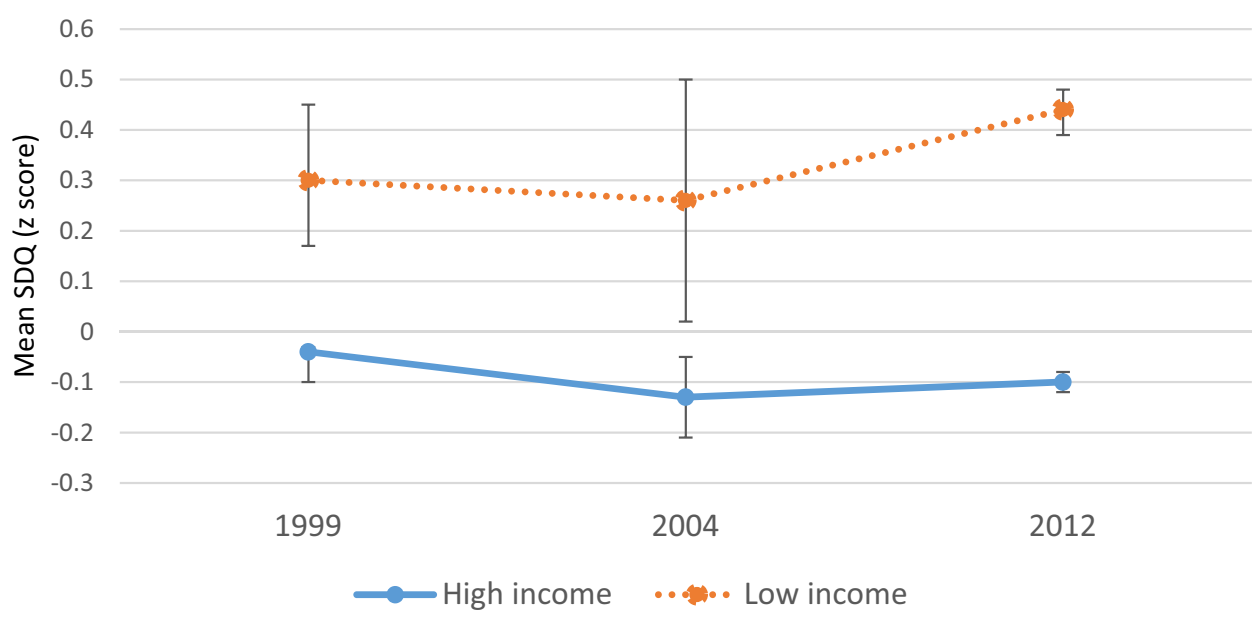

Panel B: Teacher-rated child mental health problems

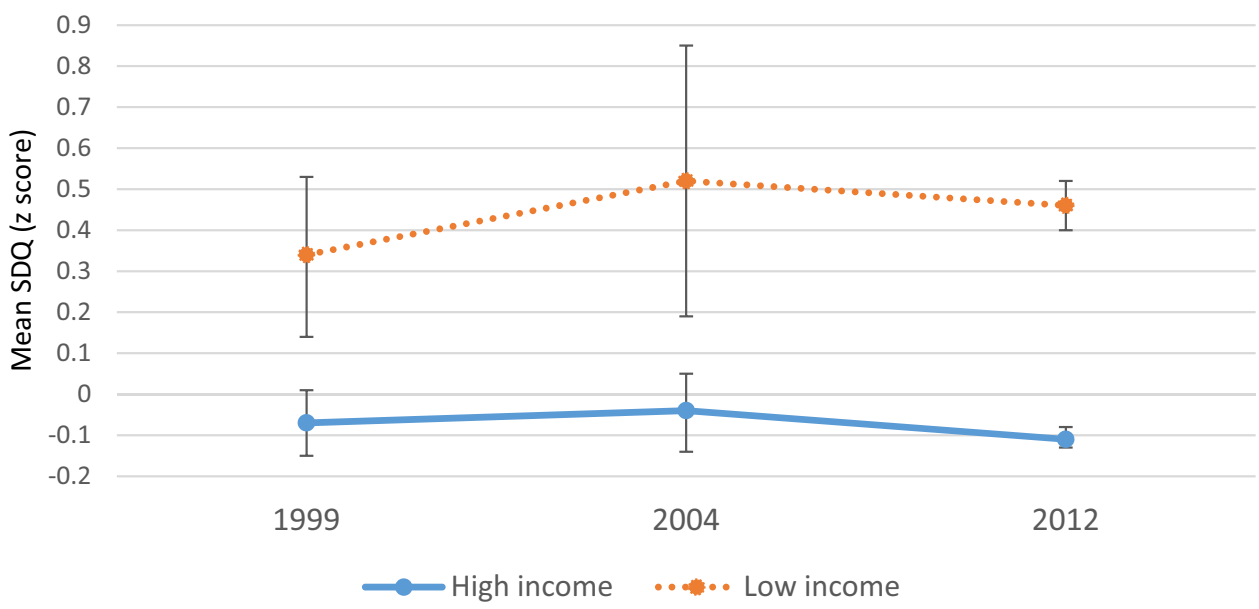




\section{Discussion}

Successive UK governments have committed to reducing inequalities in child health and to improving children's mental health $[1,2]$. However, inequalities in children's physical health are growing [3], and our study confirms that there are also substantial inequalities in child mental health. The mental health gap between advantaged and disadvantaged children is not reducing and may be getting worse. This has important implications for the future given that more than half of all adult mental disorders are preceded by mental health problems in childhood [8]. These findings on their own do not address reasons for inequalities in mental health, but evidence from intervention and quasi-experimental designs suggests that family poverty does likely have causal effects on child mental health $[9,10]$. There have been substantial public spending cuts in many European countries, including the UK, which over the past decade have disproportionately impacted household incomes, financial security, public support, health programs and mental health services for the most disadvantaged families in society [11]. The findings represent an urgent call to action to close the substantial gap in mental health between poor and better off children, to prioritise social policy that mitigates the impacts of public spending cuts on the most vulnerable families in society, and to make appropriate adjustments in service provision in community and health care settings to support the mental health of children from low-income families.

Funding This work was supported by the Medical Research Council [Grant No. MR/J01348X/1] and by support to RS from ESRC [ES/ N003098/1].

\section{Compliance with ethical standards}

Conflict of interest On behalf of all authors, the corresponding author states that there is no conflict of interest.

Ethical standards The British Child and Adolescent Mental Health Surveys and Millennium Cohort Study received ethical approval from the Multi-Centre Research Ethics Committee. Parents in all three studies provided informed consent.
Open Access This article is distributed under the terms of the Creative Commons Attribution 4.0 International License (http://creativeco mmons.org/licenses/by/4.0/), which permits unrestricted use, distribution, and reproduction in any medium, provided you give appropriate credit to the original author(s) and the source, provide a link to the Creative Commons license, and indicate if changes were made.

\section{References}

1. Her Majesty's Treasury (2003) Every child matters (Green Paper). The Stationery Office, Norwich

2. Prime Minister's Office (2016) Statement from the new Prime Minister Theresa May. Speech delivered on 13 July 2016. https:// www.gov.uk/government/speeches/statement-from-the-new-prime -minister-theresa-may

3. Royal College of Paediatrics and Child Health (2017) State of Child Health. Report 2017. RCPCH, London

4. Gore-Langton E, Collishaw S, Goodman R, Pickles A, Maughan B (2011) An emerging income differential for adolescent emotional problems. J Child Psychol Psychiatry 52(10):1081-1088

5. Collishaw S (2015) Annual research review: secular trends in child and adolescent mental health. J Child Psychol Psychiatry 56:370-393

6. Collishaw S, Goodman R, Ford T, Rabe-Hesketh S, Pickles A (2009) How far are associations between child, family and community factors and child psychopathology informant-specific and informant-general? J Child Psychol Psychiatry 50:571-580

7. Goodman R (2001) Psychometric properties of the Strengths and Difficulties Questionnaire. J Am Acad Child Adolesc Psychiatry 40:1337-1345

8. Kim-Cohen J, Caspi A, Moffitt TE et al (2003) Prior juvenile diagnoses in adults with mental disorder: developmental followback of a prospective-longitudinal cohort. Arch Gen Psychiatry 717-709(7):60

9. Costello EJ, Compton SN, Keeler J, Angold A (2003) Relationships between poverty and psychopathology: a natural experiment. J Am Med Assoc 290:2023-2029

10. Yoshikawa H, Aber JL, Beardslee W (2017) Austerity and health: the impact in the UK and Europe. Eur J Public Health 27(4):18-21

11. Stuckler D, Reeves A, Loopstra R et al (2017) Austerity and health: the impact in the UK and Europe. Eur J Public Health 27(4):18-21 